\title{
Microsatellite Markers for the Chameleon Grasshopper (Kosciuscola tristis) (Orthoptera: Acrididae), an Australian Alpine Specialist
}

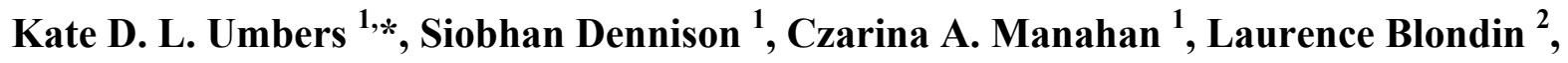
Christine Pagés ${ }^{2}$, Ange-Marie Risterucci ${ }^{2}$ and Marie-Pierre Chapuis ${ }^{2}$

1 Department of Biological Sciences, Macquarie University, Sydney, NSW 2109, Australia; E-Mails: siobhan.dennison@mq.edu.au (S.D.); czarina_112@hotmail.com (C.A.M.)

2 CIRAD, UPR Bioagresseurs analyse et maîtrise du risque, F-34398 Montpellier, France; E-Mails: laurence.blondin@cirad.fr (L.B.); christine.pages@cirad.fr (C.P.); ange-marie.risterucci@cirad.fr (A.-M.R.); marie-pierrre.chapuis@cirad.fr (M.-P.C.)

* Author to whom correspondence should be addressed; E-Mail: kate.umbers@mq.edu.au; Tel.: +61-2-9850-6279.

Received: 4 September 2012; in revised form: 18 September 2012 / Accepted: 19 September 2012 / Published: 24 September 2012

\begin{abstract}
A set of polymorphic loci was characterised using an enrichment library for the Australian alpine specialist, the chameleon grasshopper (Kosciuscola tristis), an atypical grasshopper known for its remarkable temperature-controlled colour change. The number of alleles per locus ranged from three to 20 and observed heterozygosity from 0.16 to 0.76 . These are the first microsatellite markers for a non-endangered Australian alpine animal and will inform questions of gene flow across the sky islands of this unique and threatened region.
\end{abstract}

Keywords: Australia; alpine; grasshopper; colour; color; thermoregulation; sexual selection; population genetics; conservation genetics; climate change; male competition

\section{Introduction}

The Australian alpine region has received little scientific attention despite its unique and threatened status [1]. Therefore, this large unspoilt stretch of wilderness harbours many new and little-known species. The Kosciuscola grasshoppers are endemic to the region with four mainland species (Kosciuscola tristis, K. usitatus, K. cognatus, K. cuneatus) and one in Tasmania (K. tasmanicus). Their 
altitudinal distribution ranges from $1000 \mathrm{~m}$ (in Tasmania) to the peak of Mt. Kosciuszko at $2228 \mathrm{~m}$ and from west of Canberra, $650 \mathrm{~km}$ south to just north of Melbourne, Victoria [2]. In Tasmania the distribution of $K$. tasmanicus spans $300 \mathrm{~km}$ along the north western alpine plateau. Though they are restricted to the comparatively small alpine region of Australia (just $0.04 \%$ of the continent), they are abundant during late summer and early autumn.

Kosciuscola grasshoppers are short-winged, flightless acridids (short-horned grasshoppers of which there are 8000 species). A most remarkable feature of this genus is that male $K$. tristis change colour in response to ambient temperature from black under $10{ }^{\circ} \mathrm{C}$ to turquoise above $25{ }^{\circ} \mathrm{C}[3,4]$. This characteristic is not known in any other group of acridid. Given its distribution, K. tristis is an important research subject for understanding distribution patterns, population structure and reproductive isolation among patches of high altitude ("sky islands") in the Australian Alps. This set of microsatellite markers is the first for an alpine invertebrate in Australia; so far only critically endangered vertebrate species with tiny populations have been genetically described because of immediate extinction risk [5,6]. This is also one of very few microsatellite sets for grasshoppers. Microsatellite data for $K$. tristis will highlight fine scale allelic distribution across their restricted range and provide greater insight into the processes important to the evolution of similarly isolated alpine species. Moreover, such data will provide a baseline from which the effects of climate change in the region can be measured as global temperatures rise.

\section{Results and Discussion}

Polymorphism and allelic distribution of eight loci were estimated for 26 K. tristis collected from one population located at Dead Horse Gap, Kosciuszko National Park, Australia using GENALEX 6.2 [7] (Table 1). PCR products labelled with different coloured fluorescent tags using the M13 tagging method (see [8]) were pooled and visualised on a 3130xl Genetic Analyser (Applied Biosystems). Allele sizes were scored using PEAK SCANNER software (version 1.0 Applied Biosystems), and each genotype was also checked by eye. In the polymorphic loci the number of alleles ranged from four to twenty (Table 2).

No loci were in linkage disequilibrium but several of the loci deviated significantly from Hardy-Weinberg equilibrium ( $p<0.01$ ) (GENEPOP 3.4, [9]) (Table 2). All showed a homozygote excess evenly distributed across allele size classes, which excludes genotyping errors as the source of disequilibrium (MICRO-CHECKER; [10]). Null alleles may have caused the observed deviation from Hardy-Weinberg equilibrium, with null allele frequencies estimated between $10 \%$ and $35 \%$ for K.tr29, K.tr30, K.tr76, K.tr82, K.tr88 (Table 2). A similar prevalence of null alleles is regularly observed in microsatellites of Orthoptera species [11-13]. Fortunately, methods are available to analyse microsatellite data in the presence of null alleles (e.g., FrEENA [12]). The deviation from Hardy-Weinberg equilibrium and reduced observed heterozygosity may be partially attributable to a Wahlund effect due to the isolated nature of the population and it is unclear for how long this population may have been isolated. The Dead Horse Gap population of $K$. tristis may have historically interbred with populations across the alpine plateau at Charlotte Pass (M. F. Day pers. comm.) but are now isolated from that population perhaps by shifts in distributions due to climatic change. Alternatively, if the population has been isolated for many generations, the excess of homozygotes 
observed in these data may represent inbreeding. Genotyping more populations will help assess whether the deviation from Hardy-Weinberg equilibrium is population-specific and shed light on gene flow and dispersal patterns within this region.

Table 1. Primer sequences, repeat motifs, size ranges Forward primers were tagged with a 5'M13 universal sequence (5'-TGTAAAACGACGGCCAGT-3'), but size ranges shown excluded this portion of the sequence and Genbank accession numbers for $K$. trisits microsatellite loci.

\begin{tabular}{|c|c|c|c|c|}
\hline Locus & Primer Sequences (5'-3') & Repeat Motif & Size Range (bp) & Genbank Accession No. \\
\hline Ktr29 & $\begin{array}{l}\text { F: TAACTGGCAGACAGGCACAC } \\
\text { R: AGGCCTTAGAGCCCAGAGAC }\end{array}$ & $(\mathrm{AC})_{19} \operatorname{atg}(\mathrm{CA})_{7}$ & 176-202 & HQ316183 \\
\hline $\mathrm{K} \operatorname{tr} 30$ & $\begin{array}{l}\text { F: GCAAATTTGGCGTCTTCATC } \\
\text { R: GTCATAAGGGCGGATACTGG }\end{array}$ & $(\mathrm{AC})_{12}$ & 144-206 & HQ316184 \\
\hline Ktr58 & $\begin{array}{l}\text { F: CAGTTACATACAGCAACATGTCTAGG } \\
\text { R: AGCTTCAAGCAAGACTGAGATG }\end{array}$ & $(\mathrm{GA})_{5} \mathrm{a}(\mathrm{AG})_{19}$ & $242-314$ & HQ316185 \\
\hline Ktr60 & $\begin{array}{l}\text { F: TCACCGGTATGGCTCTTAGG } \\
\text { R: TTCGGCGTGAAGACGTAAC }\end{array}$ & $(\mathrm{TG})_{18}$ & $218-254$ & HQ316186 \\
\hline Ktr 73 & $\begin{array}{l}\text { F: GGGAATTTGAATCTGTGATCG } \\
\text { R: CACGACGTTGTAAAACGAC }\end{array}$ & $(\mathrm{TG})_{10} \mathrm{ta}(\mathrm{TG})_{8}$ & $242-250$ & JX843414 \\
\hline Ktr76 & $\begin{array}{l}\text { F: GTAACTGAGCACCTGGCACA } \\
\text { R: GCAGACCGAGGATGAGAAAG }\end{array}$ & $(\mathrm{TG})_{12}$ & $234-238$ & HQ316187 \\
\hline Ktr82 & $\begin{array}{l}\text { F: TCCAGTCTTGTCAGGAAATACG } \\
\text { R: TGCTGCAATCTCATCAATGG }\end{array}$ & $(\mathrm{TG})_{19}$ & 196-218 & HQ316188 \\
\hline Ktr88 & $\begin{array}{l}\text { F: ACATGCCGGTGCCATTTAC } \\
\text { R: CAATGATTTCCGTGGATACG }\end{array}$ & $(\mathrm{AC})_{8} \mathrm{aa}(\mathrm{AC})_{20}$ & $176-216$ & HQ316189 \\
\hline
\end{tabular}

Table 2. Characteristics of microsatellite loci for Kosciuscola tristis.

\begin{tabular}{lccccccccccc}
\hline Locus & Dye & $\mathbf{P f}(\boldsymbol{\mu M})$ & $\operatorname{Pr}(\boldsymbol{\mu M})$ & $\mathbf{M g C l}_{\mathbf{2}}(\boldsymbol{\mu M})$ & $\boldsymbol{N}$ & $\boldsymbol{N}_{\text {test }}$ & $\boldsymbol{N}_{\mathbf{A}}$ & $\boldsymbol{H}_{\mathbf{O}}$ & $\boldsymbol{H}_{\mathbf{E}}$ & $\boldsymbol{p}$ & Null Allele Freq. \\
\hline $\mathrm{K} t r 29$ & $\mathrm{f}$ & 0.02 & 0.10 & 2.0 & 26 & 26 & 15 & 0.692 & 0.907 & 0.32 & 0.10 \\
$\mathrm{~K} t r 30$ & $\mathrm{p}$ & 0.03 & 0.10 & 2.5 & 24 & 26 & 16 & 0.333 & 0.907 & $<0.01$ & 0.30 \\
$\mathrm{~K} t r 58$ & $\mathrm{p}$ & 0.03 & 0.10 & 2.5 & 24 & 26 & 4 & 0.583 & 0.497 & 0.82 & 0.00 \\
$\mathrm{~K} t r 60$ & $\mathrm{n}$ & 0.03 & 0.10 & 2.5 & 25 & 26 & 17 & 0.760 & 0.874 & 1.00 & 0.03 \\
$\mathrm{~K} t r 73$ & $\mathrm{f}$ & 0.02 & 0.10 & 2.5 & 25 & 30 & 3 & 0.160 & 0.215 & 0.42 & 0.07 \\
$\mathrm{~K} \operatorname{tr} 76$ & $\mathrm{v}$ & 0.02 & 0.10 & 2.5 & 23 & 26 & 20 & 0.435 & 0.910 & $<0.01$ & 0.25 \\
$\mathrm{~K} t r 82$ & $\mathrm{n}$ & 0.02 & 0.10 & 2.5 & 25 & 26 & 12 & 0.200 & 0.852 & $<0.01$ & 0.35 \\
$\mathrm{~K} \operatorname{tr} 88$ & $\mathrm{v}$ & 0.03 & 0.10 & 2.5 & 23 & 26 & 12 & 0.565 & 0.868 & 0.03 & 0.15 \\
\hline
\end{tabular}

Dye: dye on M13 tag used for each locus (p: pet, f: fam6, v: vic, n: ned), Pf: forward primer concentration; Pr: reverse primer concentration, $\mathrm{MgCl}_{2}$ : concentration; $N$ : number of grasshoppers successfully genotyped; $N_{\text {test }}:$ number of samples for which amplification was attempted, $N_{\mathrm{A}}$ : number of alleles; $H_{\mathrm{O}}$ : observed heterozygosity; $H_{\mathrm{E}}$ : expected heterozygosity; $p$ : probability of deviation from Hardy-Weinberg equilibrium, Null Allele Freq.: null allele frequencies computed with the method of [14] using FrEENA [12]. 


\section{Experimental Section}

A partial DNA library of recombinant clones was obtained from a single $K$. tristis individual originating from Dead Horse Gap, following the enrichment protocol from [15]. Total genomic DNA was extracted using salting-out [16] and digested using Rsal restriction enzyme. Digested DNA was ligated to oligo adapters Rsa21 and 5'-phosphorylated Rsa25, pre-amplified by polymerase chain reaction (PCR) using the adapter primers and purified (QIAquick PCR purification kit, QIAGEN). Biotinylated oligo probes $\mathrm{I}(\mathrm{GA})_{15}$ and $\mathrm{I} 8(\mathrm{GT})_{15}$ were hybridized to the ligated DNA and captured using streptavidin magnetic particles (Promega). The oligo adapter Rsa21 was used as primer to perform PCR on the microsatellite-enriched eluates. The amplification products were ligated into a plasmid vector (pGEM-T Easy, Promega) and transformed into ElectroMAX DH10B T1 resistant cells. Recombinant colonies were randomly selected and cloned inserts were amplified with the Rsa21 primer. The PCR products were transferred to nylon membranes (Hybond Inc) and probed with ${ }^{32}$ P-labelled sequences complementary to the microsatellites $(\mathrm{CT})_{15}$ and $(\mathrm{CA})_{15}$.

Screening of 288 cloned fragments identified 116 positive transformants (40\%). Among them, 89 inserts were sequenced (performed by Cogenics). Forty-two of these sequences were excluded because of similar flanking sequences that were detected using the program MiCROFAMILY (i.e., 47\% [17]). High levels of similarity between flanking regions of microsatellite-containing sequences is often found in grasshoppers $[11,18]$. We selected 24 of the unique sequences, with an adequate flanking sequence size, for polymerase chain reaction (PCR) amplification.

Primers were designed for 24 sequences containing microsatellite repeats (PRIMER 3 PLUS). PCRs were $10 \mu \mathrm{L}$ reactions containing $50 \mathrm{ng}-100 \mathrm{ng}$ of genomic DNA, $200 \mu \mathrm{M}$ of each dNTP, $2 \mu \mathrm{L}$ of $5 \times$ GoTaq FlexiBuffer (Promega) and $0.02 \mu \mathrm{M}$ fluoro-labelled tag, with locus-specific primer and $\mathrm{MgCl}_{2}$ concentrations (Table 2). The greatest resolution for all primer pairs was found with the following protocol: one initial denaturation at $94{ }^{\circ} \mathrm{C}$ for $3 \mathrm{~min}$, then denaturation: $30 \mathrm{~s}$ at $94{ }^{\circ} \mathrm{C}$, annealing: one cycle each at $60{ }^{\circ} \mathrm{C}, 58{ }^{\circ} \mathrm{C}, 56{ }^{\circ} \mathrm{C}, 54{ }^{\circ} \mathrm{C}$ and $52{ }^{\circ} \mathrm{C}$, then 35 cycles at $50{ }^{\circ} \mathrm{C}$ for $30 \mathrm{~s}$, extension: $72{ }^{\circ} \mathrm{C}$ for $45 \mathrm{~s}$, and a final extension step of $72{ }^{\circ} \mathrm{C}$ for $10 \mathrm{~min}$ (MJ Research PTC100 Thermocycler). PCR product was visualised on $2 \%$ agarose gels with HyperLadder IV (BIOLINE) and eight primer pairs were selected based on reproducible amplification and absence of aspecific bands.

\section{Conclusions}

This set of microsatellite loci is the first for a non-endangered Australian alpine animal. These loci provide us with the opportunity to gather baseline data on an abundant and ecologically important species in this region. This is significant because the Australian alpine ecosystem is highly threatened by climate change.

\section{Acknowledgments}

Funding was obtained from Macquarie University's Research Excellence Scholarship (Umbers). 


\section{References}

1. Hennessy, K.; Fitzharris, B.; Bates, B.C.; Harvey, N.; Howden, S.M.; Hughes, L.; Salinger, J.; Warrick, R. Australia and New Zealand. Climate Change 2007: Impacts, Adaptation and Vulnerability. In Proceedings of Contribution of Working Group II to the Fourth Assessment Report of the Intergovernmental Panel on Climate Change, Cambridge, UK, 2007; pp. 507-540.

2. Rehn, J.A.G. Family Acrididae: Subfamily Cyrtacanthacrldinae tribes Oxyini, Spathosternini, and Praxibulini. In The Grasshoppers and Locusts (Acridoidea) of Australia; CSIRO: Melbourne, Australia, 1957.

3. Key, K.H.L.; Day, M.F. The physiological mechanism of colour change in the grasshopper, Kosciuscola tristis Sjöst. (Orthoptera: Acrididae). Aust. J. Zool. 1954, 2, 340-363.

4. Umbers, K.D.L. Turn the temperature to turquoise: cues for colour change in the male chameleon grasshopper (Kosciuscola tristis) (Orthoptera: Acrididae). J. Insect Physiol. 2011, 57, 1198-1204.

5. Morgan, M.J.; Hunter, D.; Pietsch, R.; Osborne, W.; Keogh, J.S. Assessment of genetic diversity in the critically endangered Australian corroboree frogs, Pseudophryne corroboree and Pseudophryne pengilleyi, identifies four evolutionarily significant units for conservation. Mol. Ecol. 2008, 17, 3448-3463.

6. Mitrovski, P.; Heinze, D.A.; Broome, L.; Hoffmann, A.A.; Weeks, A.R. High levels of variation despite genetic fragmentation in populations of the endangered mountain pygmy-possum, Burramys parvus, in alpine Australia. Mol. Ecol. 2007, 16, 75-87.

7. Peakall, R.O.D.; Smouse, P.E. GenAlEx 6: Genetic analysis in Excel. Population genetic software for teaching and research. Mol. Ecol. Notes 2006, 6, 288-295.

8. Boutin-Ganache, I.; Raposo, M.; Raymond, M.; Deschepper, C.F. M13-tailed primers improve the readability and usability of microsatellite analyses performed with two different allele-sizing methods. Biotechniques 2001, 31, 24-28.

9. Raymond, M.; Rousset, F. GENEPOP (Version 1.2): Population Genetics Software for Exact Tests and Ecumenicism. J. Hered. 1995, 86, 248-249.

10. Van Oosterhout, C.; Hutchinson, W.F.; Wills, D.P.M.; Shipley, P. Micro-CHECKER: Software for identifying and correcting genotyping errors in microsatellite data. Mol. Ecol. Notes 2004, 4, 535-538.

11. Chapuis, M.-P.; Popple, J.-A.; Simpson, S.J.; Estoup, A.; Martin, J.-F.; Steinbauer, M.; Mcculloch, L.; Sword, G.A. Eight polymorphic microsatellite loci for the Australian plague locust, Chortoicetes terminifera. Mol. Ecol. Res. 2008, 8, 1414-1416.

12. Chapuis, M.-P.; Estoup, A. Microsatellite null alleles and estimation of population differentiation. Mol. Biol. Evol. 2007, 24, 621-631.

13. Blanchet, E.; Pages, C.; Blondin, L.; Billot, C.; Rivallan, R.; Vassal, J.; Lecoq, M.; Risterucci, A. Isolation of Microsatellite Markers in the Calliptamus genus (Orthoptera, Acrididae). J. Ins. Sci. 2010, 10, 1-6.

14. Dempster, A.P.; Laird, N.M.; Rubin, D.B. Maximum likelihood from incomplete data via the EM algorithm. J. Roy. Stat. Soc. B 1977, 39, 1-38.

15. Billotte, N.; Lagoda, P.J.L.; Risterucci, A.-M.; Baurens, F.-C. Microsatellite-enriched libraries: applied methodology for the development of SSR markers in tropical crops. Fruits 1999, 54, 277-288. 
16. Sunnucks, P.; Hales, D.F. Numerous transposed sequences of mitochondrial cytochrome oxidase I-II in aphids of the genus Sitobion (Hemiptera: Aphididae). Mol. Biol. Evol. 1996, 13, 510-524.

17. Meglécz, E. Microfamily (version 1): A computer program for detecting flanking-region similarities among different microsatellite loci. Mol. Ecol. Notes 2007, 7, 18-20.

18. Berthier, K.; Loiseau, A.; Streiff, R.; Arlettaz, R. Eleven polymorphic microsatellite markers for Oedaleus decorus (Orthoptera, Acrididae), an endangered grasshopper in Central Europe. Mol. Ecol. Res. 2008, 8, 1363-1366.

(C) 2012 by the authors; licensee MDPI, Basel, Switzerland. This article is an open access article distributed under the terms and conditions of the Creative Commons Attribution license (http://creativecommons.org/licenses/by/3.0/). 